\title{
EMC studies on systems with hybrid filter circuits for modern aircraft applications
}

\author{
T. Kut ${ }^{1}$, B. Chand ${ }^{1}$, A. Lücken ${ }^{2}$, S. Dickmann ${ }^{1}$, and D. Schulz ${ }^{2}$ \\ ${ }^{1}$ Institute of Fundamentals of Electrical Engineering, Helmut Schmidt University, Hamburg, Germany \\ ${ }^{2}$ Institute of Electrical Power Systems, Helmut Schmidt University, Hamburg, Germany \\ Correspondence to: T. Kut (tobias.kut@hsu-hh.de)
}

\begin{abstract}
In this contribution, a new approach for EMCfilter design is presented. Due to the increasing electrification of modern aircraft, as a result of the More Electric Aircraft concept, new strategies and approaches are required to fulfill the strict EMC aircraft standards (DO-160/ED-14 - Sec. 20). Consequently the weight and volume of the used filter components can be reduced. A promising approach could be a combination of passive and active filters. For the same attenuation effect, so-called hybrid filters achieve either savings in weight and volume, or can obtain an additional filtering effect with minimal weight increase of an existing system. In this paper, the underlying theory is explained in detail, carried out in a simulation tool and the gained insight is demonstrated with a sample measurement.
\end{abstract}

\section{Introduction}

In order to reduce the environmental impact of aircraft and to improve the overall system efficiency, global efforts for reducing the aircraft weight are underway. One key issue is the wide application of electric system components instead of heavy mechanical, pneumatic and hydraulic systems (Fig. 1). This approach to change the power supply structure of an aircraft is already known as More Electric Aircraft (MEA) concept. Within this concept the traditional Auxiliary Power Unit (APU) could be replaced by a Multifunctional Fuel Cell System (MFFCS). Therefore, it is necessary to transform the load-dependent fuel cell output voltage by DC/DC converters. To avoid exceeding the EMI limits for power electronics, filter circuits are necessary. These passive filter elements take up a relatively large part of the overall system weight and can be reduced in size only by increasing the switching frequency. In some applications, the EMC filters represent more than one third of the total power sup-

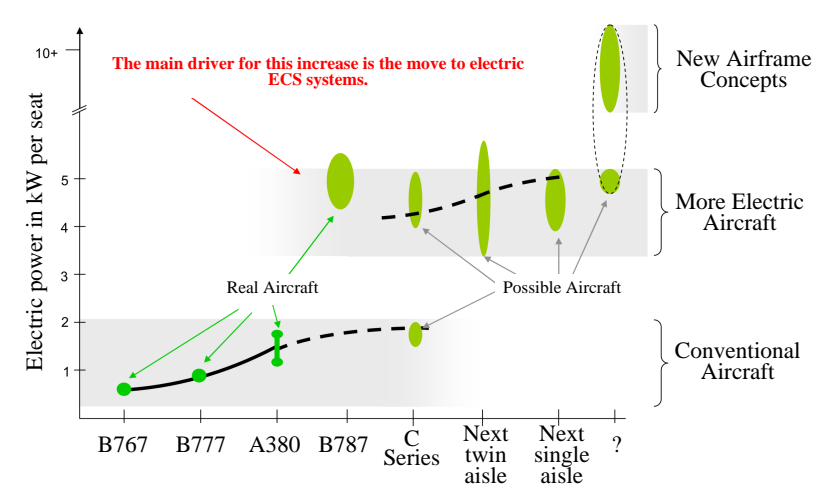

Fig. 1. Increasing electrical power demand in civil aerospace (McLoughlin, 2009).

ply volume or weight. For this reason some electromagnetically integrated EMC filter structures (van Wyk et al., 2005; Waffenschmidt et al., 2005) and also active EMI filters for printed circuit boards (PCBs) and low power applications (Biela et al., 2006; Son and Sul, 2003) have been proposed. In this paper a new EMI filter structure for DC aircraft applications is presented, which allows a significant reduction of the filter weight or an increasing filter attenuation with minimal additional weight.

\section{Hybrid filter topology and its basic operating principle}

The proposed concept for the size and weight reduction of EMI filters is the use of both active and passive filters in one system, commonly called hybrid filter, instead of fully passive filters. High frequency active filters are broadly employed in signal processing and communications engineering. However, those applications operate with low current 
a)

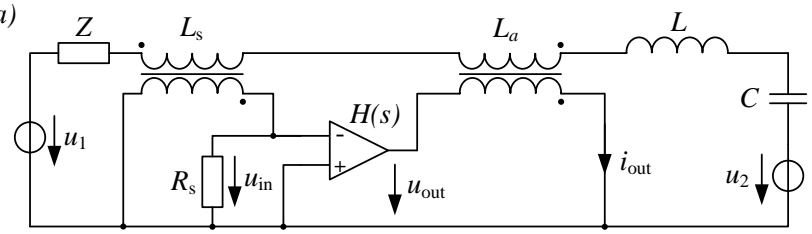

c)

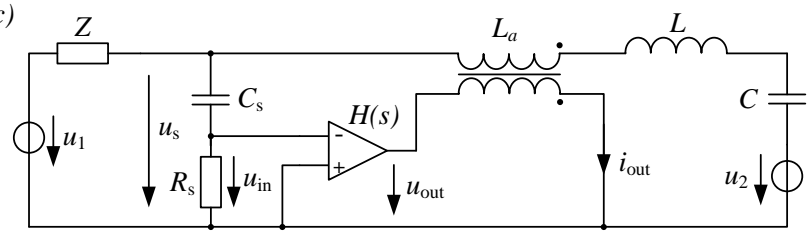

b)

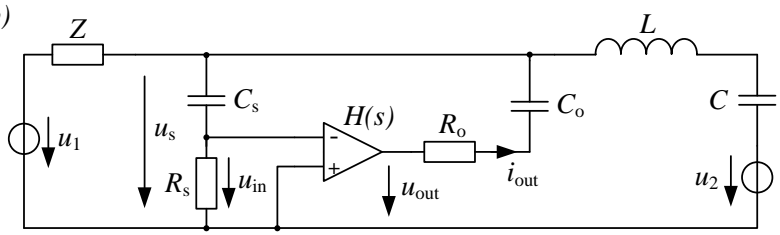

d)

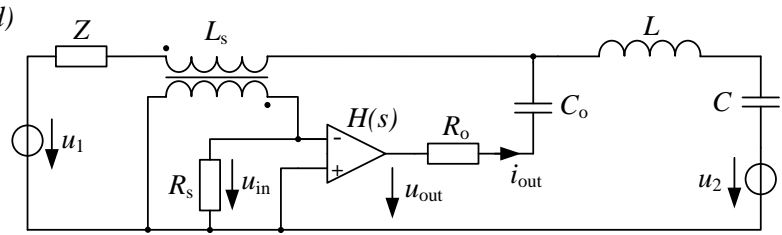

Fig. 2. Different active filter structures for single phase circuits as basic design example.

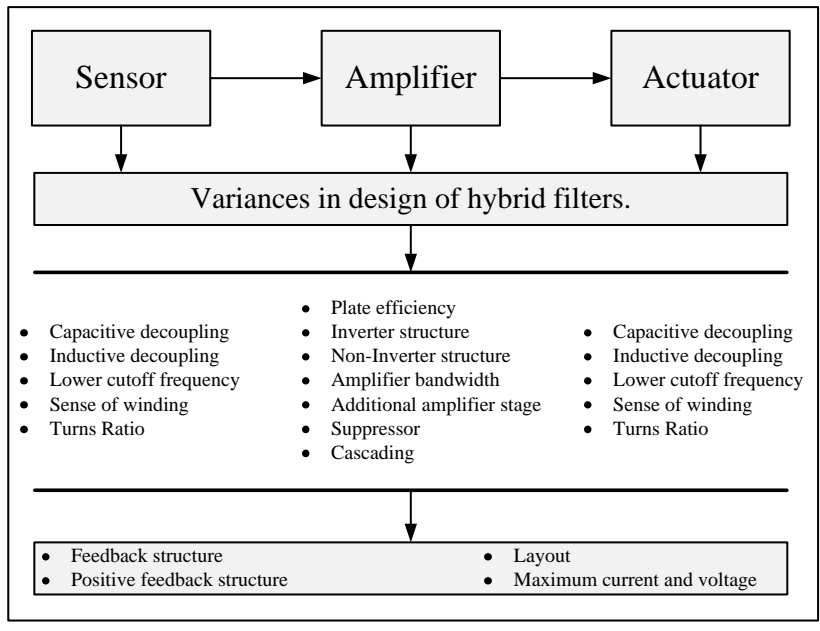

Fig. 3. Basic structure and possible variances in design of hybrid filters.

and voltage levels. For higher power levels, as in aircraft applications, the construction of such systems becomes critical. Wide-band amplifiers have to be used, which should be able to handle high current and voltage levels. This challenge motivates research in this field and is addressed in the following.

For the design of a hybrid EMC filter the knowledge about the different possible active filter structures is essential. Basically four types of circuits (Heldwein et al., 2006) are known in the literature and shown in Fig. 2. The basic strategies rely on the measurement of either current (Fig. 2a and d) or voltage (Fig. 2b and c) (Larsen, 1998; Hironobu, 2003; Honda, 2003; Pelly, 2009) and in the injection of a current (Fig. 2a and c) or a voltage (Fig. $2 b$ and d) to the DC lines. Here, it is obvious that for the integration of active filters into an existing filter network three additional elements must be taken into account. The main task is to decouple the interference signal with a sensor (capacitive or inductive). Subsequently, the signal is rotated by 180 degrees in phase and amplified in the amplitude. This signal is fed back via an actuator (capac- itive or inductive) into the existing system. Another degree of freedom (Fig. 3) is, the phase shift is achieved by an inverter or the inversely arranged and coupled inductors. The voltage/current cancelation operates in the limited frequency range from approximately $10 \mathrm{kHz}$ (low pass character at decoupling) up to $5 \mathrm{MHz}$ (bandwidth of the amplifier). The limited bandwidth of the amplifier requires a reduction of the gain at higher frequencies in order to guarantee stability of the system.

\section{Simulation results}

The basic topology of Fig. 2c was converted into a simulation model. To demonstrate that this approach has advantages over a conventional purely passive filter architecture, a hybrid filter architecture in the simulation was examined more closely. A promising approach (Rehfeld, 2012) for the integration of this active filter section is shown in Fig. 4. It is a simple common-mode filter, consisting of Y-capacitors, and a common-mode choke, supplemented by the active part and excited with a common mode interference. The network is terminated by a conventional Line Impedance Stabilization Network (LISN). By measuring the voltages across the resistors $R_{\mathrm{m}}\left(U_{\text {out }}\right)$ and $R\left(U_{\text {in }}\right)$ and the subsequent forming of the quotient $\left(U_{\text {out }} / U_{\text {in }}\right)$ of these two voltages, the transfer function $Z(s)$ of each applied filter circuit can now be calculated. These are presented in comparison in Fig. 5. Here, it becomes clearly visible that the hybrid filter structure for the entire $\mathrm{kHz}$-range has significant benefits over the passive filter structure. This frequency range is particularly important and interesting because the passive components designed for this purpose have a high weight and volume. As described in the previous section, the active filter characteristic is in the lower frequency range $(1-10 \mathrm{MHz})$ affected by the coupling characteristic and the upper frequency range is limited $(1-10 \mathrm{MHz})$ by the respective bandwidth of the operational amplifier. Nevertheless, it is clear that through the implementation of the hybrid filter design advantages in order to save 


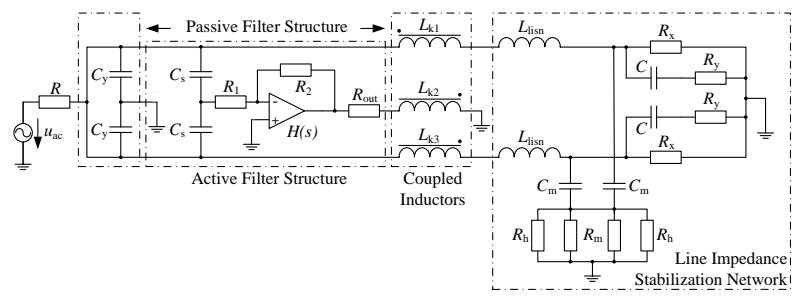

Fig. 4. Schematic of the simulated hybrid filter structure.

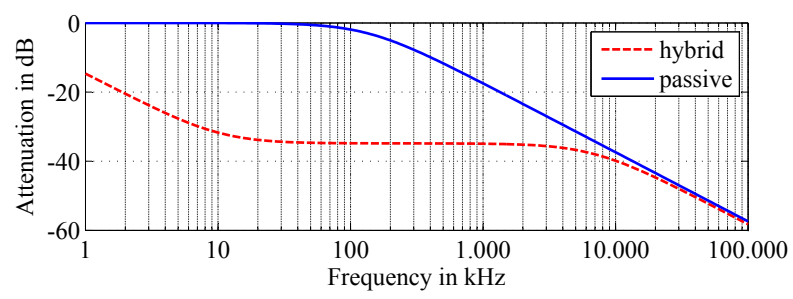

Fig. 5. Comparison of passive and hybrid filter structure simulation results.

weight and/or to increase the available filter attenuation can be achieved. Here, the next step is the consideration of parasitic elements which should be determined from practical measurements and/or an evaluation of mathematical models.

\section{Transfer function of hybrid filters}

To describe the frequency characteristic of a filter circuit, it is possible to determine it using the method of transfer functions. At higher order filters (series connection of single filters), this method becomes very complex. Another possibility is described below.

\subsection{Mathematical description}

The $\underline{\mathbf{A}}$ matrix method (Fig. 6) is another way to determine the transfer function. It is based on the fact that each twoport network, which is an electrical system, is described by a matrix.

$$
\left(\begin{array}{c}
\underline{U}_{\text {in }} \\
\underline{I}_{\text {in }}
\end{array}\right)=\underline{\mathbf{A}} \cdot\left(\underline{U}_{\text {out }}\right)
$$

$\underline{\mathbf{A}}=\left(\begin{array}{l}\underline{a}_{11}=\left.\frac{\partial U_{\text {in }}}{\partial U_{\text {out }}}\right|_{I_{\text {out }=0}} \underline{a}_{12}=\left.\frac{\partial U_{\text {in }}}{\partial I_{\text {out }}}\right|_{U_{\text {out }=0}} \\ \underline{a}_{21}=\left.\frac{\partial I_{\text {in }}}{\partial U_{\text {out }}}\right|_{I_{\text {out }=0}} \underline{a}_{22}=\left.\frac{\partial I_{\text {in }}}{\partial I_{\text {out }}}\right|_{U_{\text {out }=0}}\end{array}\right)$

The advantage for higher order filters is that the matrices of the single filters can easily be multiplied together to obtain a matrix for the overall system $-\underline{\mathbf{A}}_{1} \cdot \underline{\mathbf{A}}_{2} \cdot \ldots \cdot \underline{\mathbf{A}}_{\mathrm{n}}=\underline{\mathbf{A}}_{\text {total }}$. From this, the transfer function can be determined as the inverse calculation of the matrix element $\underline{a}_{11}$.

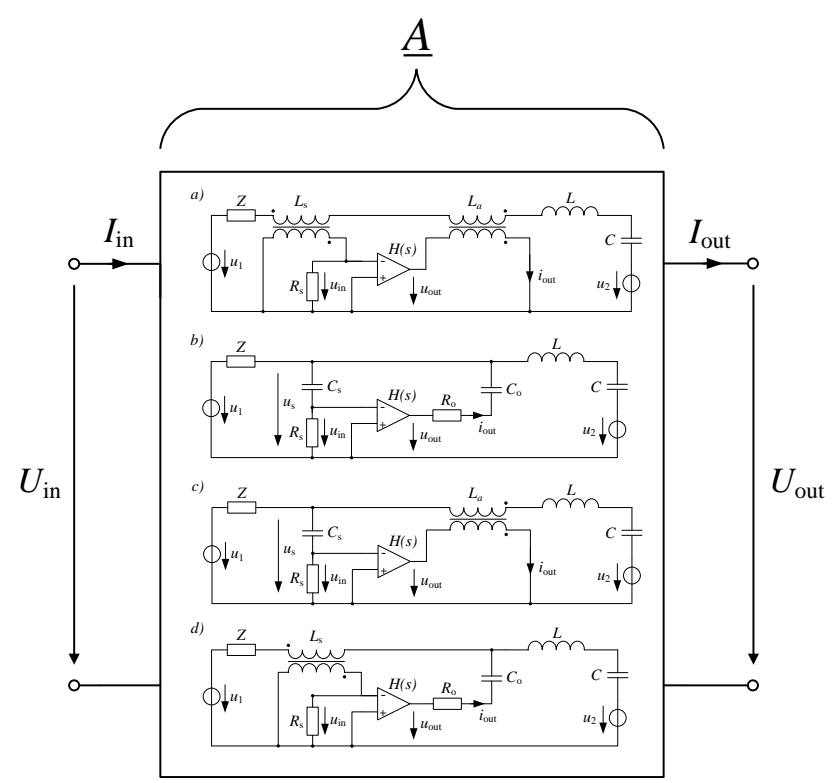

Fig. 6. Mathematical description of filters using $\underline{\mathbf{A}}$ matrices.

The calculation of the matrix element $\underline{a}_{11}$, for example for the circuits presented in Fig. $2 b$ and d yields to the following transfer functions. These two filters have the best filter characteristic for this DC aircraft application here. To simplify this, the following assumptions have been made: the power supply as well as the operational amplifier are ideal. The variables $T_{1}$ to $T_{4}$ describe the input and output impedances, consisting of $C_{S} / R_{S}$ and $C_{o} / R_{o}, \kappa$ describes the gain of the operational amplifier. In order to distinguish the individual elements they are described better by their input and output characteristics. This means for example that the element $\underline{a}_{11-\mathrm{LC}}$ is coupled via an inductor and the amplified signal is fed back through a capacitor.

$\underline{a}_{11-\mathrm{CC}}=\frac{s^{2} T_{3}^{2}+s T_{4}+1}{s^{2} \kappa T_{1}^{2}+s T_{2}+1}$

$\underline{a}_{11-\mathrm{LC}}=\frac{s^{2} T_{2}^{2}+s T_{3}+1}{s T_{1}+1}$

Based on this filter transfer functions, the matrices were calculated and carried out in a filter simulation tool.

\subsection{Implementation in a filter design tool}

For various filter circuits (active and passive) these matrices are integrated into a filter design tool (Rehfeld, 2012; Kut et al., 2012). Using a graphical user interface boundary conditions of the filter can be defined. These are the minimum and maximum values of the used inductors, capacitors and resistors. Other input parameters are the attenuation within a given frequency band, the input and output impedance and 


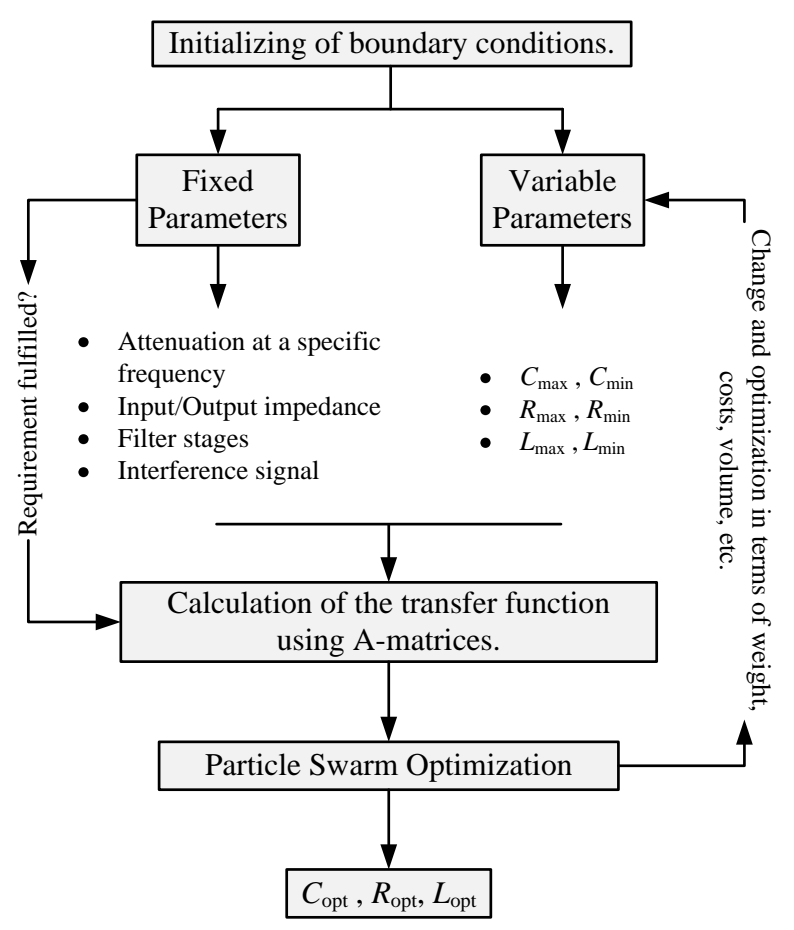

Fig. 7. Flowchart of the filter design procedure.

the number of filter stages (Fig. 7). The optimization in terms of weight, costs, volume, etc. is done by using an algorithm, which is called Particle Swarm Optimization (PSO). The output parameters of the script are the calculated filter elements for the practical implementation $\left(C_{\mathrm{opt}}, R_{\mathrm{opt}}, L_{\mathrm{opt}}\right)$.

\section{Practical implementation of the analyzed filter}

Based on the results of the filter design tool, various filter circuits have been selected, designed, developed and measured. Then, these filter topologies were tested for two different DC/DC converters (Fig. $8 \mathrm{~b}$ and c). Firstly, this filter principle has been tested on a $2 \mathrm{~kW}-\mathrm{DC} / \mathrm{DC}$ converter and secondly on a $10 \mathrm{~kW}-\mathrm{DC} / \mathrm{DC}$ converter. Here, the conducted interference in the frequency range of $1 \mathrm{kHz}$ to $30 \mathrm{MHz}$ were measured. The two used DC/DC converters are designed as interleaved converters (Fig. 8a). This means that several stages are connected in parallel. The respective semiconductors are switched on and off at different time steps. This has the advantage that the storage throttle can actually be designed for a smaller current. In this respect the current ripple can also be reduced. This decreases the overall weight and there are less electromagnetic interference.

Previous studies (Rehfeld, 2012; Wagner, 2012) have shown that a hybrid filter with an inductive decoupling and capacitive coupling (Fig. 2c) has the best filter characteristic for this application here. Therefore, this filter is used.
Table 1. Comparison of passive and hybrid amplitudes.

\begin{tabular}{ccccc}
\hline & Frequency & Passive & Hybrid & Gain \\
\hline 1 & $300 \mathrm{kHz}$ & $71 \mathrm{~dB}$ & $52 \mathrm{~dB}$ & $19 \mathrm{~dB}$ \\
2 & $600 \mathrm{kHz}$ & $54 \mathrm{~dB}$ & $40 \mathrm{~dB}$ & $14 \mathrm{~dB}$ \\
3 & $900 \mathrm{kHz}$ & $37 \mathrm{~dB}$ & $27 \mathrm{~dB}$ & $10 \mathrm{~dB}$ \\
\hline
\end{tabular}

\section{Measurement results}

In order to check whether these benefits of the hybrid filter structure can be confirmed by practical measurements, an EMC measurement was performed with DC/DC converter presented in the previous section. Except for the spectrum analyzer the total test setup was integrated into an EMC anechoic chamber to minimize interference from outside. The test setup inside the anechoic chamber is shown in Fig. 9.

Here, a DC source is designed so that it acts as a fuel cell and the electronic load is configured so that it operates similarly as consumer in an electrical aircraft grid. Between these two components the power electronics will be installed with the additional hybrid filter. To differentiate the source and the load, LISNs were installed on both sides. Furthermore, a monitoring unit for controlling and additional auxiliary power supplies are also installed. The interference, recorded with the spectrum analyzer are measured directly on the $50 \Omega$ output of the LISN.

Firstly, the disturbance of the DC/DC converter with a conventional passive filter and secondly with the new hybrid filter structure was measured. The results are shown in Fig. 10. There, once again it shows that with the use of a hybrid filter architecture, the filter attenuation could also be increased and measured in practical applications. The increase of the filter attenuation at the characteristically designed switching frequency $(4 \times 75 \mathrm{kHz})$ and its harmonics is compared for discrete frequency points in Table 1.

These findings show that this hybrid filter concept presented here has advantages not only in the simulation, but can also lead to benefits in practical measurements in the filtering of power electronic circuits. As inverse conclusion can be stated that the possible increase of the filter attenuation can be certainly used to design the corresponding passive filters smaller and to save finally weight and volume. The $10 \mathrm{~kW}$ DC/DC converter (PCB, components, heat sink, control, etc.) weighs about $2230 \mathrm{~g}$ with passive filters and with hybrid filter with similar filter characteristics (mainly through downsizing and weight reduction of the storage throttle) about $2000 \mathrm{~g}$. In this case, savings of around $10 \%$ are possible.

\section{Conclusions}

The installation of electric system components instead of heavy mechanical, pneumatic and hydraulic systems in 

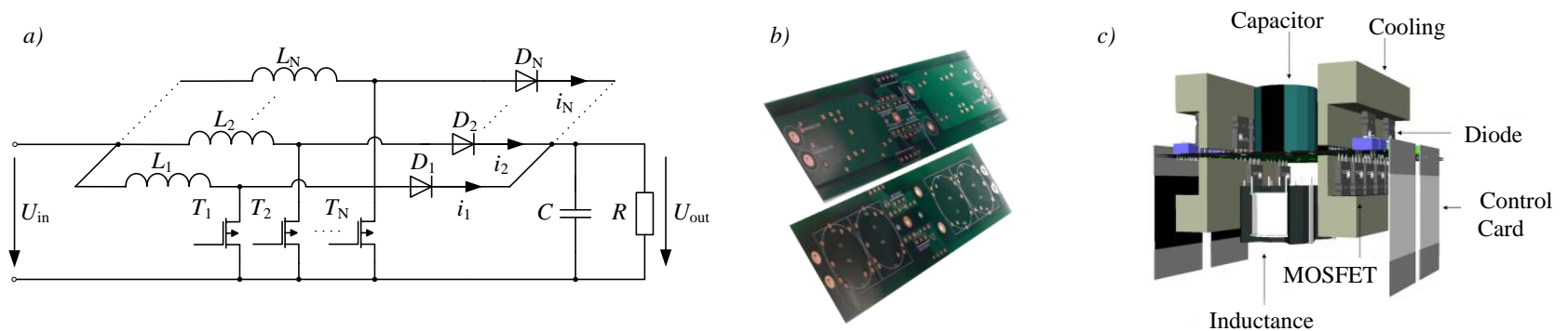

Fig. 8. (a) Principle of an interleaved converter as boost, (b) Printed circuit board of a 2 kW-DC/DC converter and (c) 3-D model of a 4-stage $10 \mathrm{~kW}-\mathrm{DC} / \mathrm{DC}$ converter.

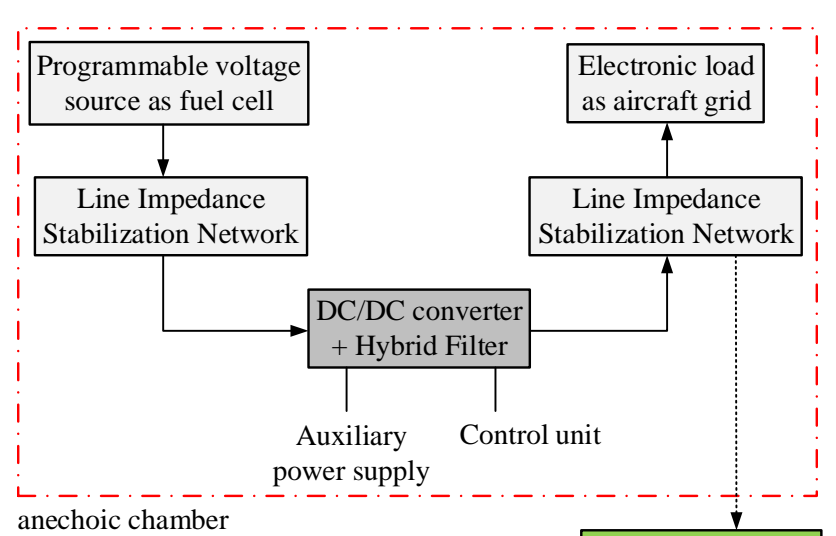

Spectrum Analyzer

Fig. 9. Measurement setup for comparison of filter structures.

modern aircraft firstly lead to weight saving effects and secondly EMC requirements (DO-160/ED-14) increased as a result of the required DC/DC converter at the output of a possible fuel cell. To make sure, that the achieved weight savings will not be compensated by an increased filter weight of the DC/DC converter, in this paper a new approach of filter topology was introduced for aircraft applications. This method relies on a combination of active and passive filter topologies. This so-called hybrid filter achieves either savings in weight and volume for the same attenuation effect, or can obtain an additional filtering effect with minimal weight increase of an existing system. Starting from the basic topologies and their operating principles, a simulation was performed which shows the advantage of such a topology. Furthermore, various filter structures were carried out in a filter design tool and described by their $\underline{\mathbf{A}}$ matrix with the aim of an automated design process. Subsequently, based on these findings various filter circuits have been selected and tested on two DC/DC converters. The results show that this hybrid filter structure has advantages not only in the simulation, but also can lead to a higher filter attenuation in order to fulfill the strict EMC aircraft standards of DC/DC converters in modern aircraft.

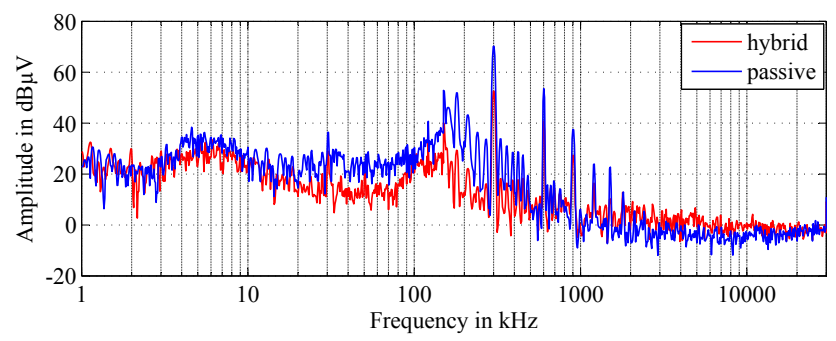

Fig. 10. Comparison of passive and hybrid filter structure meausurement results.

\section{References}

Biela, J., Wirthmueller, A., Waespe, R., Heldwein, M., Kolar, J., and Waffenschmidt, E.: Passive and active hybrid integrated EMI filters, in: Applied Power Electronics Conference and Exposition, 2006, APEC '06, Twenty-First Annual IEEE, 7 pp., doi:10.1109/APEC.2006.1620688, 2006.

Heldwein, M., Ertl, H., Biela, J., and Kolar, J.: Implementation of a transformer-less common mode active filter for off-line converter systems, in: Applied Power Electronics Conference and Exposition, 2006, APEC '06, Twenty-First Annual IEEE, 7 pp., doi:10.1109/APEC.2006.1620696, 2006.

Hironobu, K.: Active Filter, Patent, JP 087973, 2003.

Honda, J.: Active EMI Filter, Patent Application, http://www. patentlens.net/patentlens/patent/WO_2004_001927_A3R4/en/, WO 2004/001927 A3R4, 2003.

Kut, T., Chand, B., Lücken, A., Dickmann, S., and Schulz, D.: Optimierte EMV-Filteranalyse für den Einsatz von brennstoffzellengespeisten Gleichspannungswandlern in modernen Verkehrsflugzeugen, in: Deutscher Luft- und Raumfahrtkongress 2012, Berlin, Germany, online available at: http://www.dglr.de/ publikationen/2012/281288.pdf, 2012.

Larsen, E. V.: Hybrid active power filter with programmed impedance characteristics, Patent, http://www.patentlens.net/ patentlens/patent/US_5737198/en/, US 5737198, 1998.

McLoughlin, A.: More electric - Ready for take off?, in: Power Electronics and Applications, 2009, EPE '09, 13th European Conference on Power Electronics and Applications, 1-7, 2009.

Pelly, B. R.: Active filter for reduction of common mode current, Patent, http://www.patentlens.net/patentlens/patent/US_ 7583136/en/, US 7583136, 2009. 
Rehfeld, M.: EMC-Studies for optimal filter design in aicraft and automotive applications, Master's thesis, Helmut Schmidt University, University of the Federal Armed Forces Hamburg, Germany, 2012.

Son, Y.-C. and Sul, S.-K.: A new active common-mode EMI filter for PWM inverter, IEEE T. Power Electr., 18, 1309-1314, doi:10.1109/TPEL.2003.818829, 2003.

van Wyk, J., Lee, F., Liang, Z., Chen, R., Wang, S., and Lu, B.: Integrating active, passive and EMI-filter functions in power electronics systems:a case study of some technologies, IEEE T. Power Electr., 20, 523-536, doi:10.1109/TPEL.2005.846553, 2005.
Waffenschmidt, E., Ackermann, B., and Ferreira, J.: Design method and material technologies for passives in printed circuit Board Embedded circuits, IEEE T. Power Electr., 20, 576-584, doi:10.1109/TPEL.2005.846530, 2005.

Wagner, R.: Design of a 4-level interleaved converter for the use of fuel cells in modern aircraft, Master's thesis, Helmut Schmidt University, University of the Federal Armed Forces Hamburg, Germany, 2012. 